\title{
DEPURACIÓN Y REFORMA DE LA ADMINISTRACIÓN DE LA JUSTICIA EN LA PROVINCIA DE ALICANTE DURANTE LA GUERRA CIVIL
}

\author{
GLICERIO SÁNCHEZ RECIO
}

\section{INTRODUCCIÓN}

Es sumamente conocido que la administración del Estado quedó paralizada e, incluso, se desarticuló con motivo de la rebelión militar de julio de 1936 y que las autoridades locales y regionales, que aseguraron su poder o que surgieron de las organizaciones revolucionarias durante los primeros días del levantamiento en armas contra la República, ocuparon el vacío de poder y lo ejercieron con unos criterios distintos e, incluso, dispares a los del gobierno central en unos y otros territorios, dependiendo de la correlación de fuerzas de las organizaciones revolucionarias.

Durante las primeras semanas del alzamiento los objetivos a alcanzar, aunque de manera confusa, eran tres: contener y reducir al enemigo que trataba de fijar y ampliar el territorio rebelde, eliminar al enemigo interno y llevar a cabo la revolución social. Ahora bien, el conseguirlo no sólo suponía grandes dificultades reales sino también un enorme esfuerzo de organización en aquellas circunstancias tan poco adecuadas para llevarlo a cabo (1).

El vacío de poder y la desorganización en la administración de la justicia tuvieron efectos fatales y de gran trascendencia: La justicia ordinaria -la histórica- quedó colapsada por las dificultades que se encontró el personal judicial, acentuadas por la tradicional desconfianza que las organizaciones proletarias sentían hacia ellos; de ahí la depuración y las persecuciones que sufrieron en algunos casos. El propio gobierno de la República dictó en los primeros días varios decretos sobre el cese de funcionarios, partidarios de la subversión o de conducta dudosa hacia el régimen (2). En algunos casos, incluso, se formaron comisiones, con pretensiones de tribunal revolucionario,

(1) Arostegui, J.: «La República en guerra y el problema del poder», en Studia Historica. Historia Contemporánea. Vol. III, número 4. Páginas 7-19. Salamanca, 1985.

(2) Decreto de la Presidencià sobre funcionarios públicos, de 21 de julio, y decreto sobre la separación preventiva de funcionarios, de 21 de agosto de 1936 (Gac. de la Rep. del 22 de julio y 22 de agosto). 
para revisar las sentencias dictadas por la justicia histórica, como el de la Oficina Jurídica de Barcelona (3). Además de lo anterior y como consecuencia de ello, los sumarios quedaron inconclusos, muchos de los detenidos y pendientes de juicio fueron liberados o se incorporaron a las organizaciones milicianas para dirigirse al frente de guerra, de la misma forma desaparecieron muchos de los tesstigos, etc. (4).

Frente al colapso de la justicia ordinaria comenzó a organizarse la justicia popular -jurisdicción especial, de excepción-, primero, por las organizaciones revolucionarias y algunos gobiernos regionales (5) y, después, por el gobierno central. A medida que éste fue recuperando el poder, la justicia popular alcanzó su máximo desarrollo convirtiéndose en la base de un nuevo modelo de administración judicial, que extendió otra vez su competencia al conocimiento de los delitos comunes (6), y en el que tanto la justicia popular como la ordinaria quedaron asumidas.

\section{LA DEPURACIÓN DE LOS FUNCIONARIOS JUDICIALES}

De acuerdo con la documentación conservada, la mayor parte de los funcionarios judiciales fueron cesados de sus puestos una vez declarada la rebelión militar. Los jueces y los fiscales municipales, tanto los titulares como los suplentes, lo fueron, de derecho, por un decreto del ministerio de justicia del 15 de agosto, pero, de hecho, ya lo habían sido en los días inmediatamente siguientes a la rebelión. En adelante se procuraría que quienes desempeñaran tales puestos fueran totalmente leales al régimen republicano (7). Lo mismo sucedió con los funcionarios de los juzgados de primera instancia e instrucción y de algunas audiencias. Así los magistrados de la audiencia de Castelión fueron cesados provisionalmente y nombrados otros para sustituir-

(3) Barriobero y Herrán, E.: Un tribunal revolucionario. Cuenta rendida por el que fue su presidente. Barcelona. 1937; y Rubio i Tuduri, M.: La justicia a Catalunya, 19 juliol 193619 febrer 1937. Páginas 14-16. Barcelona, 1937.

(4) AHN. (C)ausa (G)eneral de Vizcaya: Informe-Resumen; Páginas 26-29. Leg. 1333(1). En términos generales, son coincidentes los informes enviados por las Audiencias de las distintas provincias que se mantuvieron leales a la República.

(5) Barriobero y Herrán, E.: Op. cit.; páginas 144-146; y AHN. C.G. de Barcelona: Pieza 5. ${ }^{a}$. Leg. 1635(1). Ver también AHN. (S)ección (G)uerra (C)ivil (de Salamanca): Sección P.S. de Gijón. Leg. 6.

(6) Sánchez Recio, G.: «La justicia popular durante la guerra civil», en Arbor. Números 491492. Páginas 158-163. Nov.-Dic. de 1986.

(7) AHN. C.G. de Valencia: Pieza 5. ${ }^{a}$ : Aparecen las relaciones de los funcionarios de la justicia municipal cesados, la mayor parte de ellos entre el 18 y el 20 de julio de 1936. Leg. 1393(1). Vol. A. 
los con carácter interino el 26 de octubre de 1936 (8), y los funcionarios de los juzgados valencianos cesaron prácticamente todos, en particular los jueces y los fiscales (9).

Los ceses impuestos por las autoridades que actuaban en nombre del frente popular fueron sancionados por los decretos del gobierno del 21 de julio, que mandaba retirar del servicio aquellos que no fueran adictos a la República, y del 21 de agosto, que ordenaba alejar preventivamente aquellos sobre cuya lealtad a la República se abrigase alguna duda, en tanto los respectivos expedientes que se abriesen no clarificaran la situación (10).

Pocos días después, por un decreto del 25 de agosto, cesaban en sus funciones los magistrados encargados de la inspección de los tribunales y se creaban unas juntas en las capitales de las regiones leales, cuyas funciones serían las «de investigar la actitud y la adhesión al régimen de los funcionarios de la administración (de justicia) cualquiera que sea su categoría y jurisdicción» (art. $2 .^{\circ}$ ). Estas juntas estarían formadas por un magistrado del tribunal supremo, nombrado por el ministro de justicia, una representación de las juntas de gobierno de los colegios de abogados de la región y de los funcionarios judiciales, y un miembro del personal auxiliar y subalterno de los tribunales (art. $3 .^{\circ}$ ). Como resultado de sus trabajos, la junta podría proponer «la jubilación, el cese, la separación o reposición, en su caso, de los funcionarios, que a virtud del expediente que tramiten ...” (art. 4. ${ }^{\circ}$ ). De acuerdo con lo anterior, por una orden ministerial del 8 de septiembre (11), se nombraba a don Mariano Granados Aguirre, para presidir la junta de inspección de tribunales de Alicante, y por otra del 14 del mismo mes quedaba formada la comisión de esta provincia (12).

Las juntas anteriores apenas pudieron llevar a cabo sus funciones, porque ni su estructura ni sus facultades las capacitaban para ello. En otro decreto del 10 de diciembre de 1936, firmado por el ministro de justicia, J. García Oliver, se concretaban las necesidades de la administración de la justicia en «la depuración del personal judicial y fiscal y auxiliar de tribunales y juzga-

(8) Orden del Ministerio de Justicia del 26 de octubre de 1936 (Gac. de la Rep. del 1 de noviembre).

(9) AHN. C.G. de Valencia: Pieza 5. «: Leg. 1393(1). Vol. A.

(10) Ver los decretos citados en Nota (2).

(11) Gaceta de la República, 9 de septiembre de 1936.

(12) La Comisión estaba formada por los siguientes señores: Don Mariano Granados Aguirre, Magistrado del Tribunal Supremo, Presidente. Don Vidal Gil Tirado, Fiscal de la Audiencia Provincial. Don Lino Martín Carnicero, Juez de Alicante. Distrito Sur. Don José López Pérez y don Ramón Clemente Torregrosa, Abogados del Colegio de Alicante, y don Maximiliano Iranzo, representante de los oficiales y auxiliares. (Gacet. de la Rep., 15 de septiembre de 1936). 
dos en sus distintas categorías» y en «reorganizar la administración de la justicia, a fin de que ésta responda a las exigencias que impone el nuevo régimen social que el Estado español va concretando en los presentes momentos" (13). En el decreto del 25 de agosto no se había tenido en cuenta a los tribunales especiales ni la presencia ni las facultades de los nuevos jurados populares. Ante estas nuevas realidades, las comisiones judiciales que se crearían en cada una de las provincias leales, en virtud del decreto del 10 de diciembre, estarían formadas por un magistrado del tribunal supremo, nombrado por el ministro de justicia, y dos vocales, que serán «dos personas de reconocida solvencia, pertenecientes a las centrales sindicales y que por su profesión no se hallen en contacto con tribunales y juzgados, propuestas por el comité ejecutivo del 'frente popular de cada provincian (art. 1. ${ }^{\circ}$ ). La primera de las funciones de esta comisión era la de «depurar la actuación y adhesión al régimen" de todos los funcionarios y personal de la administración de la justicia de las audiencias, juzgados de primera instancia e instrucción y municipales. Una vez efectuada la depuración, la comisión debería enviar al ministerio de justicia «propuesta fundamentada de separación, jubilación o ratificación» de cada uno de los funcionarios y empleados (art. 3. ${ }^{\circ}$ ).

Por una orden ministerial del 7 de febrero de 1937 (14) se concretaban y especificaban las propuestas que las comisiones debian realizar al ministerio sobre ratificación o rectificación de propuestas anteriores (art. 2. ${ }^{\circ}$ ), nombramiento para los cargos que estén vacantes o que resulten en adelante (art. $1 .^{\circ}$ ) y para el resto de los cargos judiciales (art. $3 .^{\circ}$ ). Para efectuar las propuestas de nombramientos se tendrian en cuenta las solicitudes presentadas con arreglo a lo establecido en el decreto del 15 de agosto (arts. $1 .^{\circ}$ y $3 .^{\circ}$ ), pero también podrian presentarse personas que no lo hubieren solicitado.

La segunda de las funciones de la comisión era la de elaborar proyectos para reorganizar la administración de la justicia en las respectivas provincias, como se verá más adelante.

\section{LA DEPURACIÓN DE LOS FUNCIONARIOS JUDICIALES EN LA PROVINCIA DE ALICANTE}

La comisión depuradora del personal judicial se constituyó en Alicante y comenzó sus sesiones el 6 de febrero de 1937. Estaba formada por don Eduardo Busquier Verdú, de la CNT, don Rafael Poveda Torregrosa, de la UGT, y la presidía don Mariano Granados Aguirre, magistrado del Tribunal

(13) Gact. de la Rep., 12 de diciembre de 1936. Preámbulo.

(14) Gac. de la Rep., 9 de febrero de 1937. 
supremo (15). Los trabajos de la comisión, al menos en la primera fase, fueron muy rápidos, porque el día 11 del mismo mes ya estaba elaborada la propuesta de depuración del personal de la audiencia provincial, del tribunal popular, del jurado de urgencia, de los cuatro juzgados especiales, de los juzgados de primera instancia y municipales y del tribunal tutelar de menores, y el día 13 se enviaba al ministerio esta propuesta, la de los nombramientos de los sustitutos y la de reorganización de la audiencia y de los juzgados de instrucción y municipales de la ciudad de Alicante (16).

La segunda y la tercera fases se llevaron a cabo entre el 25 de marzo y el uno de abril y durante ellas se efectuaron la depuración y reorganización de los juzgados de primera instancia y municipales. En la última fecha, el presidente de la comisión se dirigía al ministro de justicia enviando las últimas propuestas y acompañándolas de la abundante documentación recogida y elaborada durante la realización de los trabajos (17).

En el informe del presidente se decía que las decisiones de la comisión se habían tomado por unanimidad y se alababan las actuaciones de los vocales «por su imparcialidad, celo, inteligencia y lealtad al régimen». Uno de los casos de posible conflicto fue el de la depuración del juzgado municipal de Elche, cuyos puestos estaban ocupados todos por miembros de la CNT, éstos eran «verdaderamente dignos y afectos al régimen», pero no estaba de acuerdo con ellos el resto de las organizaciones y partidos del frente popular, que proponían otra candidatura. Ante esta situación, considerando que «en un régimen de mayorías, son efectivamente de importancia estas objecciones y propuestas; mas como la administración de la justicia es un servicio público de evidente trascendencia, sobre el cual no deben gravitar las pasiones políticas ...», la comisión, según consta en el acta correspondiente al 27 de marzo, se abstuvo de emitir un juicio y presentó los hechos al ministro de justicia, para que éste «con profundidad de juicio y serenidad de espíritu» tomara la decisión que fuera más adecuada (18).

Los criterios aplicados para efectuar la depuración de los funcionarios judiciales fueron los de la competencia, eficacia y adhesión absoluta al régimen. Para ello se llevó a cabo una fase previa de documentación mediante la petición de informes a las organizaciones y partidos del frente popular y otras exploraciones realizadas por la propia comisión.

(15) La presidencia de la comisión se ha deducido de las firmas que acompañan a cada una de las actas de las reuniones.

(16) AHN. C.G. de Alicante: Pieza 5. ${ }^{a}$, fol. 388-389, 408-412. Leg. 1397(1).

(17) AHN. C.G. de Alicante: Ib., fol. 435-438.

(18) Ibidem, fol. 431-432. 
De acuerdo con los resultados obtenidos y con lo previsto en el artículo $3 .^{\circ}$ del decreto del 10 de diciembre de 1936, la comisión proponía la ratificación o la sanción y ésta revestía tres formas:

a) Separación del servicio con pérdida de cargo y derechos, que se imponía a los no adictos al régimen.

b) Jubilación, aplicada solamente por razones de edad o impedimento intelectual o físico para el ejercicio del cargo.

c) Cese, sin otra calificación, en los casos que exista algún tipo de incompatibilidad con otros cargos, ausencias justificadas durante largo tiempo, analfabetismo o falta de idoneidad por otros motivos, que no les hacen aptos para ell ejercicio de sus obligaciones (19).

Según esto, el resultado de la primera fase de la depuración, relativa a la audiencia provincial, a los tribunales y juzgados de la ciudad de Alicante, había sido:

\section{1) Audiencia Provincial}

a) Confirmación: La mayoría de los funcionarios, incluidos el presidente, dos fiscales y el vicesecretario. Los puestos de los magistrados se hallaban vacantes.

b) Jubilación: Un oficial primero de sala.

c) Cese: Un auxiliar de secretaría, cuyo expediente fue más tarde revisado y rehabilitado (20).

d) Traslado: Dos funcionarios: un secretario y un fiscal.

2) Tribunal Popular, Jurado de Urgencia y Juzgados Especiales

Confirmación de todos, excepto la excedencia concedida a un juez del juzgado especial número 1.

3) Juzgados de Primera Instancia e Instrucción (Norte y Sur)

a) Confirmación: La mayoría de los funcionarios.

b) Jubilación: Un oficial habilitado (Norte) y un agente judicial (Sur).

c) Separación: Dos, los médicos forenses de uno y otro juzgados.

d) Traslado: El juez titular y el interino del juzgado del Sur.

(19) Ibidem, fol. 424-425. Acta del 25 de marzo de 1937.

(20) Ibidem, fol. 433. Acta del 27 de marzo de 1937. 
4) Juzgados Municipales (Norte y Sur)

a) Confirmación: La mayoría de los funcionarios. Se hallaban vacantes los puestos de los jueces titulares.

b) Jubilación: Un oficial (Norte).

c) Separación: Cinco funcionarios: Los fiscales titular y suplente del Norte, y el fiscal suplente, el secretario interino y un oficial del Sur.

\section{5) Tribunal Titular de Menores}

a) Confirmación: El auxiliar.

b) Separación: El presidente.

c) Cese: El secretario por incompatibilidad con el cargo que está desempeñando (21).

Por lo tanto, la depuración de los funcionarios judiciales en la ciudad de Alicante no alcanzó niveles de gran dureza, aunque hay que tener en cuenta que los titulares de algunos cargos habian sido nombrados después del 18 de julio, como el propio presidente de la Audiencia, y los tribunales y los juzgados de la jurisdicción especial popular se habían formado entre agosto y octubre de 1936, de acuerdo con la nueva legislación. Unicamente fueron separados seis funcionarios, dos cesados, uno de los cuales fue repuesto, y cuatro jubilados.

Mayor variedad y dureza resultaron de la depuración de los juzgados de primera instancia e instrucción. De los datos relativos a doce juzgados, todos los de la provincia excepto el de Denia, que comprenden ochenta funcionarios, según se desprende de la relación elaborada por la comisión, los efectos de la depuración fueron los siguientes (22):

Funcion.

Idem/Conf. Vacan. Cese Sepa. Trasl. Jub. Total

Jueces

Secretarios

Oficiales

Oficial 2. ${ }^{\circ}$

Auxiliares

Médic. Forense

Med. Foren. Sust.

Agentes judic.

TOTAL

\begin{tabular}{rrrrrrr}
1 & 3 & 3 & 3 & 2 & - & 12 \\
1 & 4 & 5 & 1 & - & 1 & 12 \\
2 & - & 6 & 2 & 1 & - & 11 \\
3 & - & 1 & 1 & - & - & 5 \\
3 & 1 & 4 & 3 & - & - & 11 \\
3 & 3 & 4 & 2 & - & - & 12 \\
2 & - & 1 & 2 & - & - & 5 \\
3 & - & 4 & 5 & - & - & 12 \\
\hline 18 & 11 & 28 & 19 & 3 & 1 & 80
\end{tabular}


Del cuadro anterior se deduce que un número importante de funcionarios $(22,5 \%)$ permanecían en sus puestos y que, probablemente, fueron confirmados, aunque no conocemos por ahora las propuestas de los nuevos nombramientos, ni las fechas en que estos funcionarios habían tomado posesión de sus puestos; en segundo lugar, fue más alto aún el de los funcionarios separados $(23,75 \%)$, que era la mayor sanción que se imponía; pero el porcentaje más alto de los funcionarios depurados (35\%) pertenece a los que fueron cesados. También hay que tener en cuenta el número de vacantes existente $(13,75 \%)$. Ahora bien, tanto las plazas vacantes como las de los sancionados con la separación y el cese, en la mayor parte de los casos estaban cubiertas provisionalmente por personas nombradas por las autoridades locales; así de las once plazas vacantes, en seis consta el nombre de los que estaban desempeñándolas, y en varias de los cesados y separados. Otro dato importante a tener en cuenta es que así como entre las plazas vacantes la mayor parte correspondían a los funcionarios de rango más alto, no sucedía lo mismo con las de los cesados y separados, de los que los mayores porcentajes correspondían a los funcionarios de escala inferior.

Dado el alto porcentaje de los funcionarios depurados y de las plazas vacantes (73,75\%), en la provincia de Alicante, como en las otras provincias de la zona leal a la República, se comprende la paralización y el colapso consiguiente de la justicia ordinaria, y más aún con el cese que se había producido de los jueces y fiscales de la justicia municipal.

\section{EL PROYECTO DE REORGANIZACIÓN}

En el artículo $4 .^{\circ}$ del decreto del 10 de diciembre de 1936 se había establecido como competencia de las comisiones judiciales el proponer la «reorganización de los tribunales y juzgados» de las respectivas provincias «procurando que su planta y distribución se ajuste a las necesidades inherentes a una buena administración de la justicia dentro de la mayor economía», también debían proponer la plantilla de personal necesaria para el correcto funcionamiento de los tribunales.

A la vista de la documentación consultada y entre tanto no se conozcan los fondos de los archivos de las audiencias provinciales, el proyecto de reorganización de la administración de la justicia en la provincia de Alicante es un auténtico adelantado en su género (23).

(21) Ibidem, fol. 408-412.

(22) Ibidem, fol. 246-248.

(23) Ibidem, fol. 390-393 y 402-406. Este tipo de documentación sólo se ha hallado para la provincia de Alicante entre las distintas consultadas. 
No era ésta la primera vez que se intentaba llevar a cabo un proyecto de este tipo, pero sí la primera, pensaba la comisión, que se daban las condiciones necesarias para lograrlo, por el control que se ejercía sobre la burocracia y la desaparición de los obstáculos caciquiles.

En los trabajos previos realizados para la elaboración del proyecto se tuvieron en cuenta datos relativos a la distribución territorial de la población, a la actividad judicial durante los tres últimos años y a la planimetría de la provincia. En particular, se valoraron en sumo grado las transformaciones que habian tenido lugar en España, y especialmente en la provincia de Alicante, durante el último siglo, desde 1834, en que se ordenó judicialmente el territorio del país, y la provincia fue dividida en quince partidos judiciales.

Las transformaciones habían sido políticas y sociales. España, a pesar de las grandes dificultades que había tenido que superar y por las que estaba pasando, poseía ya una larga tradición liberal y democrática y se habían establecido unas relaciones entre las clases sociales muy distintas a las de 1834. Las transformaciones económicas habian sido también intensas y Alicante, en 1930, contaba con otros centros comerciales e industriales modernos, además de los antiguos; finalmente, había sido de gran importancia la transformación de las comunicaciones y los transportes, particularmente el ferrocarril y el automóvil, que habian acercado los pueblos a las capitales de los partidos judiciales y éstas a la capital de la provincia.

Ante tales cambios cabía perfectamente plantearse una reordenación judicial del territorio, que supusiera un ahorro a la hacienda pública, manteniendo la rapidez y la eficacia con la que debe administrarse la justicia. Ahora bien, la redistribución judicial del territorio podría afectar negativamente a algunas cabezas de partido si perdían la condición de tales; sin embargo, el criterio a seguir sería el de trasladar las capitales a los centros que en el momento desempeñaban mayor actividad económica y social y lógicamente debería desplazarse a ellos la capitalidad judicial por la influencia que estaban ejerciendo sobre los municipios de la comarca.

Los criterios seguidos por la comisión para llevar a cabo la reorganización de la administración de la justicia en la provincia fueron:

1) Reducción del número de partidos judiciales.

2) La distancia máxima que debería haber entre los pueblos más alejados y la capital del partido no sobrepasaría los 50 kilómetros y las vías serían accesibles.

3) Las capitales de los partidos judiciales, aparte de reunir las condiciones requeridas en el apartado anterior, han de ser «núcleos urbanos de polarización económica, industrial, comercial, etc.». 
4) Los nuevos partidos judiciales no tendrán una población superior a los 100.000 habitantes cada uno.

5) Las segregaciones y agregaciones de términos municipales que han de hacerse deberán ser beneficiosas para la vida y la actividad de los pueblos afectados.

6) El volúmen de asuntos civiles y criminales que se produzcan en el partido no debe exceder «la capacidad de atento conocimiento por parte del funcionario o funcionarios que deban tramitarlos y resolverlos».

Aplicando los principios anteriores, los quince juzgados de primera instancia, existentes en la provincia de Alicante, se reducian a siete:

\begin{tabular}{lll} 
Nuevos & & Antiguos \\
\cline { 1 - 1 } Alicante & & Alicante (norte y sur) \\
Benidorm & & Villajoyosa y Callosa de Ensarriá \\
Denia & & Denia y Pego \\
Alcoy & & Alcoy, Cocentaina y Jijona \\
Elda & & Villena, Monóvar y parte de Novelda \\
Elche & & Elche, parte de Novelda y parte de Dolores \\
Orihuela & Orihuela y parte de Dolores
\end{tabular}

Las hovedades más importantes de la nueva organización judicial serían la formación de los nuevos partidos judiciales de Benidorm y de Elda. En el documento que reproducimos en el apéndice pueden verse los comentarios puntuales sobre cada partido que realizaba la comisión, y en el mapa de los antiguos partidos judiciales puede observarse la racionalidad de la distribución territorial del proyecto, algunas de cuyas ideas se llevaron a la práctica treinta años más tarde, en la década de los sesenta, con la constitución del partido judicial de Elda y la desaparición de los de Monóvar, Novelda, Dolores, Callosa de Ensarriá, Pego y Cocentaina.

Por último, aunque no conocemos la propuesta de nombramientos para los nuevos juzgados, nos ha quedado constancia de los criterios a seguir en la formación de las nuevas plantillas de funcionarios, de los que se deduce también la pretensión de un ahorro en gastos de personal. En ellos se mezclan los deseos reformistas de la comisión con la esperanza de instaurar un nuevo tipo de sociedad en la que se generen menos confictos internos y la creencia en una mayor efectividad del gobierno. Esos criterios eran: 
1) Descenso del número de pleitos y causas criminales por el agotamiento económico producido por la guerra.

2) Simplificación de los trámites procesales por efecto de la nueva legislación.

3) Posible creación de los tribunales de trabajo, que apartará de la jurisdicción civil un buen número de asuntos.

4) El mayor rendimiento exigido a los funcionarios para hacer desaparecer el parasitismo burocrático.

5) Los estímulos populares de la nueva justicia.

6) La estructura orgánica que se adivina en las disposiciones ministeriales respecto a los tribunales de justicia ordinaria y la posible instauración de los tribunales itinerantes de circuito (24).

Resumiendo, por lo tanto, durante la guerra civil no sólo se organizó la justicia popular y se depuró al personal de la justicia histórica sino que se elaboraron proyectos razonables y viables para reformar la justicia ordinaria, que, como ya se sabe, debía integrarse en la primera.

(24) Ibidem, fol. 402-403. 


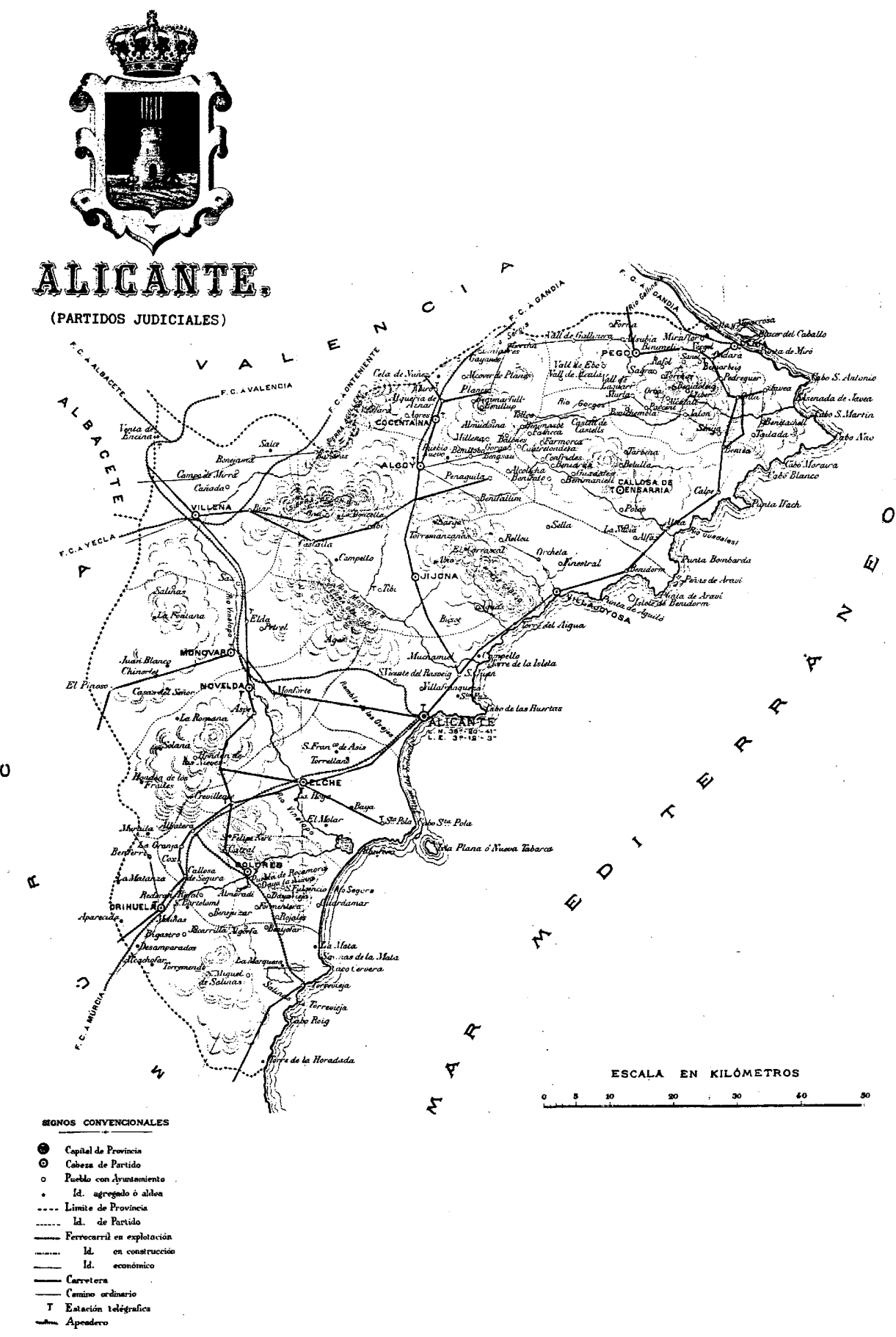


Apéndice documental

OBSERVACIONES ESPECIALES 


\section{JUZGADO DE ALICANTE}

En la propuesta de su reorganización, entregada ya al Ministerio de Justicia, como fruto de la primera etapa de trabajo de esta Comisión, se consignan los fundamentos a que responde.

Se complementa en la presente con la agregación al partido de la capital de los Juzgados Municipales de Busot y Aguas de Busot correspondientes en la actualidad al limítrofe de Jijona, por la proximidad a Alicante y la mayor facilidad y economía de las comunicaciones con esta urbe.

\section{JUZGADO DE DENIA}

Formará la demarcación nordeste de la provincia y lo integrarían todo el territorio de los partidos actuales de Denia y Pego. El segundo es de reducido contingente de asuntos judiciales y se corresponde geográficamente con el de Denia mediante una red de comunicaciones que facilitan la concurrencia a Denia de los habitantes del resto de esta circunscripción, sin que ninguno de los pueblos -aún los más lejanos de la capitalidad- se halle situado a superior distancia de 50 kilómetros.

Además se agrega el término municipal de Benisa, perteneciente ahora al partido judicial de Callosa de Ensarriá, por que su incrustación topográfica dentro del partido de Denia (que lo rodea por tres partes) racionalmente le hace recaer dentro del ámbito circundante, sin perjuicio alguno para los justiciables y antes bien con mejora de situación, ya que se halla más próximo a Denia que a Callosa de Ensarriá. 


\section{JUZGADO DE BENIDORM}

Se forma con los de Callosa de Ensarriá y Villajoyosa, salvo la segregación del Ayuntamiento de Benisa. Resulta armónica la coyuntura de ambos, porque son de análogas características. Pero la circunstancia de que las actuales capitalidades de ambas resultan desplazadas en relación con los territorios de sus respectivas adherencias, se idea la colocación de la sede central en Benidorm, puerto de mar, muy industrioso y de importancia innegable, con estación de ferrocarril y que recogeria equitativamente la afluencia judiciaria de toda la amplia comarca.

\section{JUZGADO DE ALCOY}

La nueva demarcación de este Juzgado viene a integrarse con los territorios de los de Cocentaina, Alcoy y Jijona, segregados de este último los términos municipales de Busot y Aguas de Busot que pasan a Alicante capital. Comprende, pues una extensa zona de terreno, limitada: Al norte, por la provincia de Valencia (Juzgados de Albaida y Onteniente); al Este por el nuevo Juzgado de Denia; al Sur por el de Alicante y al Oeste por el de Elda.

Basta repasar la estadística de los asuntos civiles y criminales correspondientes a los tres Juzgados refundidos para comprender que la acumulación no recarga excesivamente la labor asignada al conjunto, según la plantilla ideal. $\mathrm{Ni}$ tampoco los intereses de los justiciables se perjudican por una prolongación del radio de acción desde el centro, que se situa en la capital de Alcoy, dotada de comunicación ferroviaria con el actual partido de Cocentaina y mediante una red muy completa de carreteras y caminos con toda el área jurisdiccional.

\section{$J U Z G A D O D E E L D A$}

Quedará situado en la parte Noroeste de la provincia, compuesto por las actuales demarcaciones de los Juzgados de Villena, Monóvar y parte norte del de Novelda. Esta refundición se impone, atendidos el volúmen jurisdiccional de los negocios cuyo conocimiento arrojan las estadísticas judiciales, y la homogeneidad de los elementos territoriales conjugados, puestos en armónica relación por el ferrocarril de M.Z.A. que los atraviesa de Norte a Sur y por una perfecta inervación de carreteras y camiones que facilitan la comunicación rápida y cómoda con la capitalidad, otorgada a Elda, centro indus- 
trial importantísimo, núcleo de actividades sociales, poderosísimas, y situado estratégicamente entre Villena, Monóvar y Novelda, que si es verdad pierden el rango de cabezas de partido, ninguna asume ahora la preferencia, que es de justicia otorgar a Elda por las condiciones relevantísimas de su valor ponderativo, núcleo urbano y privilegiado arraigo territorial.

\section{JUZGADO DE ELCHE}

Se integrará con el resto del partido de Novelda (términos municipales) (términos municipales de Aspe, Hondón de las Nieves y Hondón de los Frailes) todo el perímetro del de Elche y la mitad oriental, aproximadamente, del de Dolores.

Con el simple exámen del mapa se advierte que todo el territorio concedido a la nueva división se comunica excelentemente con la ciudad de Elche, elegida como sede del Juzgado. En efecto: el ferrocarril de Alicante a Murcia, Cartagena y Torrevieja, así como la múltiple red de carreteras y otras pistas secundarias comunica todos los términos municipales asignados, con la capitalidad situada a menos de 50 kilómetros de los pueblos más alejados, tales como Guardamar del Segura por un lado y Hondón de los Frailes por el otro.

El número de pleitos civiles, causas criminales y otros negocios jurídicos, avocados a su competencia, es evidentemente racional para un conocimiento inteligente y rápido a cargo de los funcionarios de la plantilla propuesta.

\section{JUZGADO DE ORIHUELA}

La composición se hace sobre la base de su actual extensión aumentada con la parte occidental del de Dolores, en la cual figuran núcleos demográficos tan importantes como Callosa de Segura, Albatera etc. situados casi a la misma distancia de Orihuela, que la que hoy los separa de Dolores. EI incremento de asuntos de toda especie jurisdiccional no altera en modo alguno la normalidad de la Administración de Justicia, que se garantíza por medio de la nueva plantilla.

Cree esta Comisión haber cumplido su deber elevando al Ministerio de Justicia la presente propuesta de reorganización de los Tribunales y Juzga- 
dos de la provincia de Alicante. Para obtener tal resultado ha sabido inspirarse en los propósitos que animan al Gobierno sobre el cardinal motivo de racionalizar la Administración de Justicia, sin más objetivo que el bien público. La ponencia consiguió sobreponerse a toda suerte de prejuicios localistas, que han sido siempre los que frustraron intentos sabios y generosos de análoga envergadura. Si el mejor criterio de la superioridad advierte errores y deficiencias en la ponencia, no serán fruto de otro cultivo que el de carecer de mejores elementos de juicio, distintos y más completos que los consultados para fundamentar la presente labor; la cual con los mayores respetos y anhelos de acierto ponemos en manos de V.E.

Alicante de Febrero de 1937. 